\section{"Special-Interest Science" Harms Diesel-Polluted Communities Like East Los Angeles}

\section{Kristin Shrader-Frechette ${ }^{1 *}$ and Catherine McQuestion ${ }^{2}$}

${ }^{1}$ Department of Biological Sciences and Department of Philosophy, University of Notre Dame, Indiana, USA

${ }^{2}$ Department of Biological Sciences, University of Notre Dame, Notre Dame, Indiana, USA
Keywords: Advanced Collaborative Emissions Study (ACES);
"Clean diesel"; Diesel exhaust; East Los Angeles; Hazardous air
pollutant

\section{Introduction}

Childhood brain tumors, most commonly neuroblastomas, are the leading cause of cancer death in US children. Most of these brain cancers are diagnosed before 5 years of age. Besides prenatal exposure to pesticides, one of the main causes of child brain tumors is exposure to diesel exhaust [1-8]. The latest (2016) government data show that for the last 10 years, annual rates of cancer incidence have been increasing 3 times faster for children under age 15 than for adults. For the last 10 years, annual rates of brain cancer have been increasing 9 times faster for children (1.8 percent/year) than for adults (0.2 percent/year). However the brain-cancer-survival rates are not increasing [9-12].

Recently three-year-old Citlalih Ramirez of East Los Angeles was diagnosed with an aggressive brain cancer, neuroblastomas. She is one of about 5,000 US infants and children diagnosed each year with brain tumors. Most children diagnosed with neuroblastomas will not see their next 5 birthdays. Because diesel exhaust is tied to brain tumors, Citlalih - like many other victims - may have been harmed by diesel exhaust in her neighborhood of East Los Angeles. It is home to the largest port complex in the US Diesel-powered ships bring goods from abroad, and national rail/trucking-hubs transport them across the US Every day 30,000-50,000large heavy-duty diesel trucks barrel through Citlalih's neighborhood. The result? The East-LA cancer rate is 19 times higher than average-US rates, and 11 times higher than already-high Los Angeles rates [13-17].

In the US, minority communities such as East Los Angeles have the highest exposures to diesel exhaust and other air toxics, while largely-white communities have the lowest [18]. Why is the rate of child cancers increasing so much faster than that that of adults, especially in hub communities? Why are rates of relatively rare brain tumors skyrocketing, with the rate of child brain tumors increasing 9 times faster than that of adults?

Children obviously are more pollution-sensitive than adults, and their detoxification mechanisms are not fully developed. Unlike adults, children also have developmental periods during which they can be permanently structurally changed, pre-programmed for later disease, death, and misdevelopment [19]. Likewise both adult and child cancer have been increasing so dramatically that genetics cannot be the major cause. Instead researchers, including those from the WHO, say "the overwhelming contribution to the causation of cancer in the population" is "the environment" [20-22]. But if environment is a major key to preventing escalating cancer rates, why doesn't government clean up diesel-hub areas like East Los Angeles? This article shows that apparent US regulatory reliance, on scientifically-flawed diesel-industry studies, is likely one reason for this regulatory failure.

*Corresponding author: Kristin Shrader-Frechette, Department of Biological Sciences and Department of Philosophy, University of Notre Dame, Indiana USA, Tel: +1 5746319192; E-mail: Kristin.Shrader-Frechette.1@nd.edu

Citation: Shrader-Frechette K, McQuestion C (2016) "Special-Interest Science" Harms Diesel-Polluted Communities Like East Los Angeles. J Community Med Public Health Care 3: 016.

Received: April 08, 2016; Accepted: May 02, 2016; Published: May 16, 2016 


\section{Methods}

This review article uses logical and methodological analysis for two main tasks. (1) It summarizes and compares diesel-caused health harm, including the US-versus-WHO scientific dispute over whether diesel is a known human carcinogen. (2) It also assesses all the scientific studies comprising the 10-year, joint US Environmental Protection Agency (EPA) and auto-industry 2015 Advanced Collaborative Emissions Study (ACES) of diesel exhaust. ACES claims "New Technology Diesel Exhaust" (NTDE), which reduces diesel pollutants, causes neither cancer nor non-cancer health harm.

\section{The dispute over diesel-assessment methods and harm}

In 2012, the International Agency for Research on Cancer (IARC), part of WHO, named diesel exhaust a known human carcinogen and called for tighter regulations. Most western nations and medical associations agreed, and Europe passed new regulations. However, partly because of the 2005-2015 joint government-oil/auto-industry study, the Advanced Collaborative Emissions Study (ACES), the US government denied that diesel is a known human carcinogen, said the scientific data are "uncertain," and failed to tighten diesel regulations. The 2015 ACES studies claim that NTDE effects are "limited to the respiratory tract," and that NTDE causes "only a few mild effects on the lungs," no cancer or serious ailments, and "no evidence of gene-damaging effects" [23,24].

Unless scientists confirm who is right about diesel harm, IARC or ACES, diesel-impacted communities across the world - like East LA - will not know whether medical science can help stop the health harm they face. One way to begin to answer the question of who is right is to see whether either of the two sets of studies, IARC or ACES, makes obvious errors in scientific method. Two recent analyses assessed the relative strengths of the IARC and ACES studies. The first analysis showed that the ACES, but not the IARC research, are fatally flawed because it neither studies what it claims, nor does so in an unbiased way. Instead ACES relies on state-variable errors (in assessing/measuring mainly $\mathrm{NO}_{2}$ and mass, not also the deadliest component of any diesel exhaust/NTDE, Diesel Particulate Matter (DPM)), and exhibits representativeness errors (in using only the healthiest animals, too-small sample sizes, and non-lifetime exposures). Despite some ACES strength, this analysis concludes that because of these fundamental scientific flaws, ACES draws no valid conclusions about diesel harm, thus does not support the claim that no new regulations are necessary to protect against diesel harm [25].

The second analysis of the ACES-versus-IARC/WHO debate shows that, consistent with IARC conclusions, DPM meets all 6 specified evidentiary criteria, any one of which is sufficient for DPM regulation as a Hazardous Air Pollutant (HAP), although regulators make unit-risk-estimate, dose-response, and mechanistic errors in denying DPM the status of a HAP [26].

\section{Using four methodological questions to assess the contro- versy}

Despite the two preceding studies, scientific work remaining to be done is assessing the current ACES-versus-IARC/WHO debate in terms of whether they avoid four basic, additional errors of scientific method: begging the question, inconsistency, making subjective judgments, and data-suppression. In other words is either of the studies guilty of any of the following methodological errors?
- Do the studies fail to provide relevant and complete empirical evidence for their fundamental claims, thus begging the question?

- Do they contradict themselves, falling into inconsistency?

- Do they make subjective/arbitrary judgments about what data are relevant?

- Do they fall into data suppression of what fails to support their conclusion?

\section{Results}

Do either the IARC or the ACES studies beg the question, fall into inconsistency, suppress data, or provide subjective/arbitrary interpretations of results? Subsequent paragraphs show that while IARC studies appear to fall into none of these errors, ACES results are compromised by all four failures.

\section{IARC, ACES, and question-begging}

The IARC studies appear not to beg the question because they are based on data from hundreds of human epidemiological studies and controlled animal experiments throughout the world, each of which independently helps confirm and replicate the results of the other studies, that diesel exhaust causes cancer. Moreover, scores of "independent" scientists from IARC and WHO, throughout the world, "unanimously" agreed that there was "compelling" and "sufficient evidence" that diesel-exhaust causes carcinogenicity in both humans and other animals. IARC also noted that while "the amount of particulates and chemicals are reduced" with so-called "clean diesel" or NTDE, the carcinogenic potential was not gone, and therefore "actions to reduce exposures should encompass workers and the general population" [27].

Does ACES provide empirical evidence for its main claims, as does IARC, or does it beg the question by assuming what it claims to show, that NTDE is not carcinogenic? As already noted, because the ACES authors use non-representative samples and incorrect state variables [25], they fall into a question-begging analysis because they assume---rather than establish---that these flawed samples and state variables are sufficient to assess diesel carcinogenicity. They beg the question of relevant state variables because they use $\mathrm{NO}_{2}$, not DPM, levels to assess harm from DPM, the most hazardous part of diesel exhaust $[23,28]$. Their reason for begging the question about DPM-assessment methods and DPM cancers? They say DPM is too difficult to measure, although many others have done so. They also say resulting cancers were related to $\mathrm{NO}_{2}$, not diesel exhaust/ DPM, a question-begging result because they assessed $\mathrm{NO}_{2}$, not diesel exhaust/DPM [23].

ACES authors also be at least four different questions when they admit "it is possible that components of NTDE other than $\mathrm{NO}_{2}$ may have contributed to the [harmful NTDE] effects reported, but the low levels of other components [like DPM] suggest that they would not be primarily responsible" [23]. This ACES admission begs the question; first, by assuming, not establishing, that low levels of DPM are insufficient to cause harm---precisely the question they are supposed to be evaluating.

Second, this ACES admission begs the question because it assumes, rather than substantiates, the obviously false assumption that degree of hazard is based only on mass ("low levels") of a substance, rather than also on its own inherent degree of toxicity or carcinogenicity. Yet obviously a millionth of a gram of extremely-hazardous material, such 
as plutonium, can be more harmful than a gram of something less hazardous. Similarly, DPM is far more hazardous than the $\mathrm{NO}_{2}$ from a single NTDE diesel engine, although the mass of the exhaust $\mathrm{NO}_{2}$ is greater than the mass of DPM.

Third, this ACES admission begs the question and falls into qualitative unscientific language by assuming that a quantitatively-undefined "low" level of DPM is insufficient to cause harm.

Fourth, this ACES admission begs the question by assuming, not establishing, that diesel components like DPM "would not be primarily responsible" for resulting cancer, because they have tested neither the relative mass nor the relative hazard of these NTDE components. Besides, even if DPM were not "primarily responsible" for responsible for cancers, this inconsistent ACES admission assumes that DPM could be responsible, just not primarily. Either diesel causes cancer or not. Even not-primarily-DPM-caused are still cancers caused by diesel.

The preceding four instances of ACES question-begging, in dismissing harm from undefined "low levels" of DPM, and instead measuring $\mathrm{NO}_{2}$ harm is like someone who deliberately looks for a neutrino with a flashlight, finds no neutrinos, then claims there are no neutrinos. Analogously, the ACES scientists use $\mathrm{NO}_{2}$ levels to look for diesel cancers, and then claim to find no diesel cancers, only $\mathrm{NO}_{2}$ cancers. This ACES question-begging are particularly erroneous because it is well established that $\mathrm{NO}_{2}$ can cause cancer. No new analysis is necessary to assess this point. A classic 2015 meta-analysis showed that scores of studies indicate that scientists know the precise dose-response curve for $\mathrm{NO}_{2}$-induced lung cancers. Each $10 \mathrm{ug} / \mathrm{m}^{3}$ increase in $\mathrm{NO}_{2}$ causes those exposed to have a 4 percent increase in lung-cancer incidence [29].

The ACES question-begging already noted is not unusual. Indeed, begging the question is typical of ACES studies, even on the issues central to the ACES conclusion. For instance, because many ACES biochemical assays lack positive controls, ACES begs the question whether these tests were sensitive enough to detect any changes [23]. Similarly, the next sections of the paper shows that ACES scientists find brain harm from NTDE but deny this harm by begging the question, not showing, that this harm is not biologically significant. Likewise later sections show ACES begs the question when it claims to find precancerous changes in a "few" subjects or in a "small" number of cases, but assumes without evidence that because of the "small" numbers, these changes are not precancerous.

\section{IARC, ACES, and the brain-inconsistency error}

How well do IARC and ACES studies avoid other errors, like inconsistency? The IARC studies avoid contradiction because they are based on consistent data from hundreds of human-epidemiological studies and controlled animal experiments throughout the world, each of which independently helped confirm and replicate the same carcinogenicity results of other studies. Moreover, scores of different, "independent" scientists from IARC and WHO, throughout the world, "unanimously" agreed that there was "compelling" and "sufficient evidence," consistent evidence that diesel-exhaust causes carcinogenicity in both humans and other animals [27].

Yet partly because ACES authors ignore the special hazards associated with most DPM, as already mentioned, they also fall into several inconsistencies, one regarding NTDE effects on the brain. One inconsistency occurs when the ACES authors
1) Claim to have done both cancer and non-cancer studies, including brain studies;

2) Admit that they found diesel damage in the brain after even limited studies;

3) Claim, after finding brain damage, to have studied only lung cancer; and

4) Then falsely claim to have found only minor respiratory effects of NTDE.

Yet preceding claims (1) and (3) contradict each other, both affirming and denying that they are studying only lung cancer - and preceding claims (2) and (4) contradict each other, affirming and denying that they found brain damage. Their claim (1) to have studied non-cancer effects remains, to date, in the title of all four of their ACES studies: "Lifetime Cancer and Non-Cancer Assessment in Rats Exposed to New-Technology Diesel Exhaust," including "Assessment of Genotoxicity and Oxidative Damage in Rats after Chronic Exposure to New-Technology Diesel Exhaust in the ACES Bioassay" [23].

After they (1) claim to assess both cancer and non-cancer diesel effects, including Genotoxicity and oxidative damage, the ACES authors (2) admit diesel-induced brain damage. They say that although brain "baseline levels of pro-inflammatory cytokines, tumor necrosis factor alpha, and interleukin-1 alpha," all evidence of oxidative damage to the brain, "were found to increase in the [forebrain or] striatum after exposure," they decided to study only lipid peroxidation in the brain, and only in the hippocampus, not the striatum of the brain. Despite limiting their brain study, they then admitted that "a few of our analyses showed statistically-significant differences between some [exposed and not exposed] groups." Yet after ignoring both study of the striatum and statistically-significant effects in the hippocampus, they beg the question. That is, they say their brain results "are not likely to be biologically important," and therefore conclude that their NTDE study "did not produce significant or persistent oxidatively induced DNA damage to rats at the exposure levels we tested" [30].

After (2) admitting they found DNA damage to the rat brain, how were ACEs authors able to deny it, especially when their diesel-exhaust studies also found brain damage [31]? Numerous well-controlled animal and human studies, including brain autopsies, show that there is no safe dose of DPM, that any DPM is associated with increased brain inflammation, cytokines, oxidative damage, and diffuse amyloid plaques, plus DNA damage to the olfactory bulb, and brain pathology that can include Alzheimer's, autism, birth defects, brain cancer, Parkinson's, and even death [32-51]. ACES scientists (3) tried to deny brain damage, saying "How...inhaled particles are mediated outside the lungs... was not the object of these studies; effects may result from...transfer of smaller-sized particles out of the lung or via...inflammatory or neurologic signaling...outside the lung" [31]. ACES thus contradicts itself in asserting both (1) and (3) because in taking brain samples and subjecting them to minimal peroxidation tests $[28,30]$, it shows it is doing non-cancer and non-lung studies and accepts claim (1). Yet the preceding quote shows they (3) deny studying brain effects. By this denial, the authors are able to make claim (4): "The effects that were observed with NTDE were limited to the respiratory tract and were mild" [23].

Similar ACES consistency problems occur regarding its claims to assess "cancer and non-cancer" and to provide the "first 
comprehensive" study of NTDE [23], and yet to ignore other obvious phenomena indicating NTDE harm. For instance, when people are subjected to DPM, the most harmful component in NTDE, the body attempts to clear this PM from organs such as the lung via the blood, then to send the recovered PM to the intestines and bowel. This is why DPM exposure is associated with a multiplicity of different organ problems, including liver and colon cancer [52-56]. ACES researchers never examine any intestinal tissue in their studies [31], yet claim their studies are "comprehensive" [23].The preceding inconsistencies are especially damning because, from an inconsistency, any claim whatsoever follows. But if any claim follows, no ACES claims can be trusted.

\section{IARC, ACES, and the cancer-inconsistency error}

ACES makes a similar, cancer-related contradiction when it claims "no evidence of cancer" and "no precancerous changes" [57], despite inflammation, oxidative stress, tissue degeneration, and both squamous metaplasia lesions and epithelial hyperplasia lesions in the nose of animals in every group in the study, including those receiving the tiniest doses of diesel exhaust [28].Oncologists have long known that hyperplasia and metaplasia lesions like those found by ACES typically lead to cancer, and that people with these lesions have much higher rates of cancer [58-64]. In fact, pathology textbooks clearly state that "in rodents, hyperplastic and metaplastic changes [precisely the changes that ACES found] ... are considered a prelude to neoplasia" or cancer $[65,66]$. Yet ACES denies that its studies showed any precancerous states [57].

\section{Subjective interpretations of ACES results}

Besides its question-begging and inconsistent interpretations of its data, ACES scientists also repeatedly give subjective, nonscientific opinions or value judgments when they should be giving substantiated, quantitative conclusions. For instance, researchers tested equal small numbers of male and female rats, but then arbitrarily rejected results that were not "concurrent in both sexes" [28]. That is, repeatedly throughout the study, female rats experienced statistically-significant, NTDE-caused harm, such as reduced lung airflow and increased inflammation, but the researchers rejected these harmful results because male rats did not have the same results. ACES also showed that male rats exposed to NTDE had statistically-significant increases in mortality but, again, because females did not exhibit the identical effects, ACES researchers rejected them on the basis of the arbitrary and incorrect assumption that male and female health effects of pollution are invalid unless they are identical. Finding consistent results in both sexes is not a necessary condition for reliable research findings, as many outcomes are far worse in one sex than in another. Indeed, this is why researchers aim to have both male and female subjects. For instance, as compared to men, women have more than double the risk of certain organ cancers from exposure to the same dose of ionizing radiation; overall, women's average rate of cancer, per unit of radiation exposure, is about 50 percent higher than that of men [67]. Similarly, many outcomes are worse for men than for women at the same exposure level. For instance, men are four or five times more likely than women to have autism spectrum disorders [68]. Hence the ACES rejection of repeated precancerous and other results that are not the same, for different sexes, is arbitrary, subjective, and incorporates a false-negative bias.

Often the subjective ACES judgments are not merely erroneous, but also contrary to actual ACES reported research findings. For instance, ACES pathologists claim finding "no evidence of cancer or precancerous lesions" [57]. Yet only 4 pages earlier, the same authors admit that rats exposed to NTDE exhibited "hyperplasia and bronchiolization considered related to inhalation of [NTDE] 2007-technology diesel exhaust.... [because] These bronchiolar lesions were...not present in most slides....The...opinion [not fact or proof] was that diesel-exhaust-related pulmonary lesions were restricted to high-exposure animals," not on "most" slides, and "were of minimal to mild severity" [57]. Similarly ACES authors admit that "most of these tests, including tumor incidence, did not show any exposure-related effects. A few statistically-significant changes were observed at one or more exposure times and almost exclusively at the highest exposure level" [57]. Or ACES authors admit NTDE induced oxidative damage in the DNA, but damage was not "significant" [30].

But how much damage is "significant"? Why should lesions or tumors "almost exclusively at the highest exposure level" be discounted? Why does damage have to appear in "most" slides, to be counted? ACES defends none of the subjective, erroneous judgments - except to admit that "all lesions were graded subjectively by a single board-certified veterinary pathologist," regarding factors such as "inflammation, cytotoxicity... and pneumocyte hyperplasia," rather than using standard quantitative, scientific, measures of these effects [28]. Thus, even ACES authors admit its cancer/precancer judgments were "graded subjectively" by one person. Obviously ACES' discovering that diesel causes cancer precursors - even those subjectively judged as "mild," and not on "most slides," contradicts the ACES claim that it found no evidence of cancer precursors [57]. ACES' subjective, non-scientific judgments about what is "minimal," "mild," and "most," does not change the fact that the lesions appear to be lung-cancer precursors. One cannot have a mild cancer precursor that is not a cancer precursor, any more than one can have a mild pregnancy that is not a pregnancy.

Subjective, nonscientific language occurs throughout the 198 pages of the four ACES studies. For instance, ACES researchers say that they observed "minor biologic changes" [23], oxidative-stress and tissue injury that were "mild" [28], "mild increases in inflammatory and oxidative stress" [28], and that "most of the statistically significant findings were significant only by trend analysis," that "the rats exhibited statistically significant" increases in "oxidative stress in the lung" and "a mild inflammatory response" [28]. Yet in calling such changes mild or minor, the ACES authors ignore the fact that increased oxidative stress "promotes tumor formation by inducing DNA mutations and pro-oncogenic signaling pathways" [69-71].They ignore the fact that increased inflammation is a necessary for cancer to occur $[72,73]$. The ACES authors likewise ignore the fact that they found blood of exposed animals showed higher eosinophils over time [28], something that can be caused by tumors. And although the authors note increases in O1-1 and cytokines, they completely ignore the fact that increased cytokine levels can promote tumors [28].

Perhaps ACES is correct that all these biometric increases are minor, not tied to precancerous states. Even if they are, ACES authors fail to explain why such changes are not precancerous. They also provide no criteria for calling some change mild or minor. For instance, when researchers say "some small changes in a few markers of oxidation stress and inflammation were detected in lung tissue, bronchoalveolar lavage fluid and blood" [23], they beg the question as to what is "small" or "few." Likewise when they say that ACES studies have a "minor limitation" in that "some biochemical assays lacked positive controls" [23], they reveal neither how many and what percentage of biochemical assays lacked controls, nor what 
makes this limitation minor. Indeed, absence of positive controls could mean their tests were not sensitive enough. Both explanations are necessary, given the earlier ACES admission that the assessments of which lesion is minor or mild are "subjective," done by one pathologist, and often include sample sizes of only 3-5 animals [28], thus likely to generate false-negative results. At worst, ACES denial of precancerous findings is false, and at best it is subjective, especially given no positive controls.

ACES researchers also use arbitrary, subjective language when they claim that "many plasma markers - several recognized as human CVD [cardiovascular-disease] risk factors---were measured in the plasma of rats exposed for up to 24 months" [74]. However, how many are "many"? Which ones and how many plasma markers are "several"? Why were all such plasma markers and risk factors not measured? How many rats, precisely, were exposed to what levels of NTDE, and for what number of months? Without answers to such questions, genuine scientific explanation fails. Hence it is impossible to know whether ACES conclusions are reliable. ACES researchers also repeatedly use the qualitative, value-laden, nonscientific language of "up to" certain doses or time periods [28]. Instead they need to tell precisely how many animals had precisely what dose and had attained precisely what month of exposure. These are important details, as many animals died, leaving only 3-5 for some groups and thus compromising the power of the studies. Such subjective, arbitrary ACES language is incompatible with science.

\section{Discussion}

How important are the preceding ACES errors of question-begging, inconsistency, and arbitrary/subjective assessments of data? They undercut ACES validity for at least three reasons, discussed in later sections. First, the errors occur on nearly every page and concern the key parameters and conclusions of the study. Second, because these errors are classic signs of false-negative conclusions (in this case, about NTDE harm), they may result from diesel and auto-industry funding for the ACES studies. Third, these errors almost always result in suppression of data contrary to study conclusions.

\section{Why ACES errors cause omitted, suppressed, and invalid data}

When one examines the ACES research, question-begging, inconsistent, subjective claims appear on virtually every page. There are 73 instances of "up to," as in "rats were exposed for up to 30 months" to NTDE [28]. But methodological validity requires knowing precisely how many animals, at precisely which exposure doses, for precisely what period of time were exposed---especially because ACES authors claimed to use 140 female rats, plus 140 male rats at each of 4 exposure levels for the study, yet later admitted that only 3-5 animals remained at some exposure levels because so many animals died $[31,75]$. This is a crucial failure, as language like "up to" hinders assessment of false-negative biases.

Similarly the ACES studies have 45 instances of "mild," 44 instances of "few," 37 instances of "several," 32 instances of "many," and so on. At each of these and other instances of qualitative, nonscientific language, the authors appear to be giving their questionable, value-laden opinions about the evidence, rather than quantitative evidence itself. Such unscientific language suggests at least two problems. First, as the subjective "opinion" language about bronchial lesions and cancer precursors suggest, the ACES authors may well have uncovered cancerous and precancerous effects of
NTDE. Second, perhaps as earlier paragraphs suggest, ACES arbitrarily decided not to call these effects "precancerous" because they revealed only "mild" effects. Yet precancerous lesions are precancerous lesions, regardless of whether they are called "mild."

The question-begging, inconsistent, and qualitative language in ACES is particularly harmful because it is virtually always used regarding key study results and key state variables, whose accuracy is essential to legitimate study results. For instance, ACES is question-begging in claiming to study NTDE, yet essentially assessing doses based only on $\mathrm{NO}_{2}$ and mass, while ignoring the most harmful part of NTDE, namely DPM. Assessing NTDE, based on mass, ignores particle size/number, the main determinants of diesel harm. Thus ACES begs the question that what it claims to study is actually what it studies, thus draws no valid conclusions about what it claims to study. Similarly, when ACES inconsistently claims both that it found lung hyperplasia, a precancerous state, yet that it found no precancerous states, its inconsistency invalidates its central conclusion that NTDE "did not induce tumors or pre-cancerous changes." ACES has similar inconsistencies regarding whether it studied only exposures to rats in midlife, the healthiest times of their lives, or "lifetime" exposures, whether it studied only lung or also non-lung effects, and so on. Likewise, when ACES uses arbitrary and subjective language like "mild" to describe precancerous lesions or DNA damage, it rejects what could challenge its conclusions. In other words, the question-begging, inconsistencies, and subjective judgments in ACES are always used in ways that allow them to dismiss results that could challenge their no-NTDE-harm conclusions $[25,26,76]$.

The ACES errors of question-begging, inconsistency, and subjective judgments compromise ACES validity because they result in data-suppression, either failing to collect data that other researchers have shown to be damning, or dismissing damning data when they find it. For instance, when ACES begs the question of NTDE harm by studying $\mathrm{NO}_{2}$ and mass, not also DPM and particle size/number, it ignores data on the deadliest effects of NTDE, already known to cause serious diesel harm. ACES thus accomplishes data suppression through omission, doing the wrong studies with the wrong methods, that collect the wrong data, then claiming no harm. Similarly, when ACES errs through inconsistency, it also suppresses data. It admits that it found precancerous states, such as lung hyperplasia, yet it dismisses and effectively suppresses these data by claiming that lesions did not appear in "most" tests, or that the effects were "mild." By dismissing precancerous, inflammatory, and DNA-damaging effects on such subjective grounds, ACES clearly is guilty of data suppression and arbitrary interpretation of the evidence. Any ACES tests showing precancerous lesions after diesel exposure, a fact consistent with the rest of the scientific literature amounts to precancerous effects, contrary to ACES data suppression. ACES inconsistencies and subjective assumptions about "mild precancerous effects" not being precancerous, amount to data suppression.

\section{Financial conflicts of interest}

The ACES errors of question-begging, inconsistency, and subjective judgments also are important because they may arise from a bias that helps explain why ACES results contradict IARC and WHO findings about diesel harm. In the foreword to the ACES studies, the Health Effects Institute (HEI) admits that it receives half its monies from the "worldwide motor-vehicle" industry, including the diesel-truck industry. Yet it is a truism among social scientists that one can predict scientific/engineering results simply by knowing the 
funder. Corporate-funded, flawed science/engineering often generates pro-industry conclusions [77-79].

Financial conflicts of interest also appear to bias ACES research because it is so contrary to scientific consensus, including IARC and WHO. ACES researchers must have known and ignored this consensus, as they address no potential IARC-WHO challenges to their work. ACES inconsistencies likewise suggest financial conflicts of interest, as contradictions never occur in good scientific work.

In all the preceding ways, ACES research is reminiscent of tobacco-industry studies, a key example of special-interest "science," "science" designed to further its funders' profits rather than truth. By 1950, medical journals had published convincing evidence of the harms of cigarettes. Yet not until 1998 did the United States succeed in regulating false tobacco claims, advertising, and marketing to children. Not until 2008 did the World Health Organization (WHO) issue its first report on global tobacco use, showing that tobacco was killing 5 million people prematurely/year. Why did partial tobacco regulations take 50 years to accomplish? One reason is that for decades, the tobacco industry created/funded scientific "front groups," such as the Center for Indoor Air Research. It paid these front-group consultants to publish "scientific" articles that denied cigarette harm and blamed non-tobacco factors, such as smokers' personal genetics, for lung and other diseases [80]. By 2006, US courts found the major cigarette makers guilty of civil fraud and racketeering, saying they had engaged in a decades-long conspiracy to deceive the public about smoking risks in order to sustain their profits. The World Health Organization agreed and said the tobacco industry was "guilty of fraud, deception and concealment" in using flawed science to deliberately lie to the people [81].

Of course, "tobacco science" or special-interest science is nothing new. Regulated industries often perform scientifically questionable studies, designed to help the industry avoid regulations. They typically pay scientists to publish studies claiming some product/pollutant is not risky, and therefore that regulations are "unjustified." When evidence of product/pollutant harm is too massive to deny, "tobacco-science" publications claim the risks are uncertain, so that regulations are "premature." Efforts to regulate pollutants - such as those from dioxin, nuclear plants, PCBs, and pharmaceuticals - to DES, Darvon, and Vioxx, all are tainted by "special-interest science," designed to further profits rather than truth. Something similar could explain the ACES errors [77,79,82].

\section{Responding to ACES objections}

Have ACES authors objected to any of the previous criticisms? In general, their objections come down to the fact that medical science showing harm from Traditional Diesel Exhaust (TDE) is not relevant to ACES NTDE research because NTDE is different from TDE. For instance, ACES pathologists cite diesel-industry authors McClellan and Hesterberg, then claim that "NTDE compared with TDE...is... quite different.... difference in the hazard of the material....Studies of the health impact of TDE exposures most likely do not reflect either the hazards or the risks from NTDE" [57]. This objection is that because NTDE employs new technology, TDE studies are largely irrelevant to NTDE, and because WHO-IARC-scientific consensus is about TDE, ACES has no need to assess IARC conclusions. ACES are right that NTDE includes new technology---such as filters and lower-sulfur fuel.

However, for two reasons, ACES is wrong that TDE is so different from NTDE that ACES need take no account of TDE data. ACES err, first, because NTDE has not removed, only reduced, DPM threats, and DPM has no safe dose. PM has a linear concentration-response relationship with no dose threshold below which harm does not occur; even the smallest PM doses are associated with carcinogenic, neurological, reproductive, cardiovascular, respiratory, and other health harm [36,49,83-92]. Even ACES (xi) admits that NTDE removes only 90 percent of DPM. Yet leaving 10 percent of something with no safe dose can cause substantial harm. The US has tens of millions of TDE engines that release hundreds of billions of pounds of DPM/year; thus even an all-NTDE US vehicle fleet would release tens of billions of pounds of DPM/year [84,93]. Currently the 15 million TDE heavy-duty trucks in the US prematurely kill approximately 21,000 Americans/year [51,94]. Thus if all these vehicles released NTDE - which ACES claims is non-carcinogenic and causes only mild effects, NTDE would still kill 2100 Americans each year---roughly the same number as killed in the infamous 9-11-01 terrorist attacks on New York.

A second reason ACES errs in neglecting diesel/DPM studies is that NTDE creates more ultrafine than was present in TDE, and it is the most hazardous DPM, TDE, and NTDE diesel-exhaust component, mainly because it has much smaller particles that are much more potent causes of oxidative stress, reactive oxidative species, and inflammation than other PM [95-101]. These small particles can directly penetrate the brain and lungs, and cause inflammation, oxidative stress, and worse, wherever the blood brings them. NTDE also has higher particle-number concentrations and higher percentages of more dangerous particles than TDE that make it more dangerous [102-104], especially because it is 50-90 percent metals, known neurotoxins [105-111]. Thus, although NTDE reduces DPM mass overall---per particle, the NTDE DPM is more hazardous than TDE DPM [112,113].

\section{How to save citlaleh and members of other communities from diesel harm}

Protecting victims of diesel pollution might best be accomplished by phasing in various strategies. One initial way is to pass regulations and use community planning to reduce PM and especially DPM exposures. Regulations might prohibit trucks/trains at hubs from idling and from travelling in residential neighborhoods. Community planning could include planting more trees along busy highways and prohibiting locating schools near major highways [114-117].

Other protections would come from EPA's regulating all diesel vehicles, not just post-2007, heavy-duty trucks that must be NTDE. Europe regulates all diesel vehicles and requires retrofits of all. There is no good reason the US cannot do the same. The US also could provide incentives for electric and hybrid vehicles and disincentives for diesel vehicles. One disincentive would be to declare diesel and DPM "hazardous air pollutants" or HAPs---which would automatically trigger more protective regulations. HAP designation makes sense because, as mentioned, US diesel exhaust causes more deaths than all the other air toxics combined [76].

Because heavy-duty diesel trucks/trains/ships are the worst diesel polluters, the best way to reduce their community-health harm would be to electrify ports, as California has begun doing [116], then extend this port-electrification, required it of all transport hubs, like that in East Los Angeles. From there, all freight across the nation could be electrified. Most freight in Europe already is electrified. There is no good reason that the same could not be done in the US [118]. 
Citation: Shrader-Frechette K, McQuestion C (2016) "Special-Interest Science" Harms Diesel-Polluted Communities Like East Los Angeles. J Community Med Public Health Care 3: 016.

\section{Conclusion}

Although NTDE or supposed "clean diesel" is better than traditional diesel exhaust, anything that releases tens of billions of pounds of pollutants that have no safe dose causes great harm - one reason that even NTDE would still kill at least 2100 Americans each year. To protect community health, especially near truck-and-train hubs and rails/highways. The US could begin by following the lead of Europe, regulating all diesel vehicles, and electrifying its freight. Flawed, bought-and-paid-for science from the diesel-vehicle industry - like that of ACES - distracts people from needed health protections.

\section{References}

1. Peters S, Glass DC, Reid A, de Klerk N, Armstrong BK, et al. (2013) Parental occupational exposure to engine exhausts and childhood brain tumors. Int J Cancer 132: 2975-2979.

2. Liu CC, Chen CC, Wu TN, Yang CY (2008) Association of brain cancer with residential exposure to petrochemical air pollution in Taiwan. J Toxicol Environ Health A 71: 310-314.

3. van Thriel C (2011) Recent research in neurotoxicology. EXCLI J 10: 135137.

4. Solomon G (2003) Brain and Central Nervous System Tumors. The Collaborative on Health and the Environment, Bolinas, CA, USA

5. von Ehrenstein OS, Heck JE, Park A, Cockburn M, Escobedo L, et al. (2015) In Utero and Early-Life Exposure to Ambient Air Toxics and Childhood Brain Tumors: A Population-Based Case-Control Study in California, USA. Environ Health Perspect.

6. Greenop KR, Hinwood AL, Fritschi L, Scott RJ, Attia J, et al. (2014) Vehicle refuelling, use of domestic wood heaters and the risk of childhood brain tumours: Results from an Australian case-control study. Pediatr Blood Cancer.

7. Poulsen AH, Sørensen M, Andersen ZJ, Ketzel M, Raaschou-Nielsen O, et al. (2016) Air pollution from traffic and risk for brain tumors: a nationwide study in Denmark. Cancer Causes Control 27: 473-480.

8. Chen M, Chang CH, Tao L, Lu C (2015) Residential Exposure to Pesticide During Childhood and Childhood Cancers: A Meta-Analysis. Pediatrics 136 719-729.

9. Ryerson AB, Eheman CR, Altekruse SF, Ward JW, Jemal A, et al. (2016) Annual Report to the Nation on the Status of Cancer, 1975-2012, featuring the increasing incidence of liver cancer. Cancer 122: 1312-1337.

10. http://www.cbtrus.org/factsheet/factsheet.html

11. Michaelis J, Kaletsch U, Kaatsch $P$ (2000) [Epidemiology of childhood brain tumors]. Zentralbl Neurochir 61: 80-87.

12. http://seer.cancer.gov/statfacts/html/all.html

13. United States Environmental Protection Agency (2013) National Air Toxics Assessment. EPA, Washington DC, USA.

14. California Environmental Protection Agency (2015) Findings of the Scientific Review Panel on The Report on Diesel Exhaust. California Environmental Protection Agency, Sacramento, California, USA

15. Cone M (2011) A toxic tour: Neighborhoods struggle with health threats from traffic pollution. Environmental Health News, Charlottesville, North Carolina, USA.

16. http://eycej.org/living-in-a-toxic-environment-isella-ramirez-3/

17. Ostrom QT, Gittleman H, de Blank PM, Finlay JL, Gurney JG, et al. (2016) American Brain Tumor Association Adolescent and Young Adult Primary Brain and Central Nervous System Tumors Diagnosed in the United States in 2008-2012. Neuro Oncol 1: 1-50.

18. Bell ML, Ebisu K (2012) Environmental inequality in exposures to airborne particulate matter components in the United States. Environ Health Perspect 120: $1699-1704$
19. Grandjean P (2012) Only One Chance. Oxford University Press, Oxford, UK.

20. Lichtenstein P, Holm NV, Verkasalo PK, Iliadou A, Kaprio J, et al. (2000) Environmental and heritable factors in the causation of cancer--analyses of cohorts of twins from Sweden, Denmark, and Finland. N Engl J Med 343: 78-85.

21. Newby JA, Vyvyan Howard C (2005) Environmental influences in cancer aetiology. J Nutr Environ Med 15: 56-114.

22. Suk WA, Ahanchian $H$, Asante KA, Carpenter DO, Diaz-Barriga $F$, et al (2016) Environmental Pollution: An Under-recognized Threat to Children's Health, Especially in Low- and Middle-Income Countries. Environ Health Perspect 124: 41-45

23. Greenbaum DS, O'Keefe RM, Shaikh R, Gale B, Adams K, et al. (2015) HEI Statement: Synopsis of Research Report 166, Parts 1-4, Effects of Subchronic Exposure of Rats and Mice to Inhaled 2007-Compliant Diesel Exhaust. In: Greenbaum DS, O'Keefe RM, Shaikh R, Gale B, Adams K, et al., (eds.). Advanced Collaborative Emissions Study (ACES), Lifetime Cancer and Non-Cancer Assessment in Rats Exposed to New-Technology Diesel Exhaust. Health Effects Institute, Boston, USA. Pg no: 1-4.

24. Health Effects Institute (2012) Study Finds Few Health Effects from New Technology Diesel Engines. Health Effects Institute, Boston, USA.

25. Shrader-Frechette K (2015) State-Variable and Representativeness Errors Conceal "Clean Diesel" Harm: Methodologically Fallacious ACES Research. J Environ Health Sci 1: 1-8.

26. Pusateri A, Shrader-Frechette K, (2015) Commentary: Flawed Scientific-Evidence Standards and Diesel Regulations. Account Res 22: 162-191.

27. International Agency for Research on Cancer (2012) IARC: Diesel Exhaust Carcinogenic. IARC, Lyon, France.

28. McDonald JD, Doyle-Eisele M, Seagrave J, Gigliotti A, Chow J, et al. (2015) Part 1: Assessment of Carcinogenicity and Biologic Responses in Rats after Lifetime Inhalation of New-Technology Diesel Exhaust in the ACES Bioassay. In: Greenbaum DS, O'Keefe RM, Shaikh R, Gale B, Adams K (eds.). Advanced Collaborative Emissions Study (ACES), Lifetime Cancer and Non-Cancer Assessment in Rats Exposed to New-Technology Diesel Exhaust. The Health Effects Institute, Boston, USA. Pg no: 9-44.

29. Hamra GB, Laden F, Cohen AJ, Raaschou-Nielsen O, Brauer M, et al. (2015) Lung Cancer and Exposure to Nitrogen Dioxide and Traffic: A Systematic Review and Meta-Analysis. Environ Health Perspect 123: 1107-1112.

30. Hallberg LM, Ward JB, Hernandez C, Ameredes BT, Wickliffe JK, et al. (2015) Part 3: Assessment of Genotoxicity and Oxidative Damage in Rats after Chronic Exposure to New-Technology Diesel Exhaust in the ACES Bioassay. In: Greenbaum DS, O'Keefe RM, Shaikh R, Gale B, Adams K, et al., (eds.). Advanced Collaborative Emissions Study (ACES), Lifetime Cancer and Non-Cancer Assessment in Rats Exposed to New-Technology Diesel Exhaust. The Health Effects Institute, Boston, USA. Pg no: 87-105.

31. Boushey H, Frampton M, Godleski J, Harkema J, Haseman J, et al. (2015) Genotoxicity Studies: Joint Assessment by the ACES Review Panel. In: Daniel S Greenbaum, Robert M O'Keefe, Rashid Shaikh, Barabara Gale, Kate Adams (eds.). Advanced Collaborative Emissions Study (ACES), Lifetime Cancer and Non-Cancer Assessment in Rats Exposed to New-Technology Diesel Exhaust. Health Effects Institute, Boston, USA. Pg no: 148, 161.

32. Fagundes LS, Fleck AD, Zanchi AC, Saldiva PH, Rhoden CR (2015) Direct contact with particulate matter increases oxidative stress in different brain structures. Inhal Toxicol 27: 462-467.

33. Costa LG, Cole TB, Coburn J, Chang YC, Dao K, et al. (2015) Neurotoxicity of traffic-related air pollution. Neurotoxicology.

34. Costa LG, Cole TB, Coburn J, Chang YC, Dao K, et al. (2014) Neurotoxicants are in the air: convergence of human, animal, and in vitro studies on the effects of air pollution on the brain. Biomed Res Int 2014: 736385.

35. Cave D (2012) Lush walls rise to fight a blanket of pollution. The New York Times, New York City, USA

36. Block ML, Calderón-Garcidueñas L (2009) Air pollution: mechanisms of neuroinflammation and CNS disease. Trends Neurosci 32: 506-516. 
Citation: Shrader-Frechette K, McQuestion C (2016) "Special-Interest Science" Harms Diesel-Polluted Communities Like East Los Angeles. J Community Med Public Health Care 3: 016.

37. Deng X, Luan Q, Chen W, Wang Y, Wu M, et al. (2009) Nanosized zinc oxide particles induce neural stem cell apoptosis. Nanotechnology 20: 115101.

38. Shwe T, Mitsushima D, Yamamoto S, Fukushima A, Funabashi T, et al. (2008) Changes in neurotransmitter levels and proinflammatory cytokine mRNA expressions in the mice olfactory bulb following nanoparticle exposure. Toxicol Appl Pharmacol 226: 192-198.

39. Yokota S, Hori H, Umezawa M, Kubota N, Niki R, et al. (2013) Gene expression changes in the olfactory bulb of mice induced by exposure to diesel exhaust are dependent on animal rearing environment. PLoS One 8: 70145.

40. Rivera-Mancía S, Pérez-Neri I, Ríos C, Tristán-López L, Rivera-Espinosa L, et al. (2010) The transition metals copper and iron in neurodegenerative diseases. Chem Biol Interact 186: 184-199.

41. Szewczyk B (2013) Zinc homeostasis and neurodegenerative disorders. Front Aging Neurosci 5: 33.

42. James SA, Volitakis I, Adlard PA, Duce JA, Masters CL, et al. (2012) Elevated labile $\mathrm{Cu}$ is associated with oxidative pathology in Alzheimer disease. Free Radic Biol Med 52: 298-302.

43. Kleinewietfeld M, Manzel A, Titze J, Kvakan H, Yosef N, et al. (2013) Sodium chloride drives autoimmune disease by the induction of pathogenic TH17 cells. Nature 496: 518-522.

44. Pentyala S, Ruggeri J, Veerraju A, Yu Z, Bhatia A, et al. (2010) Microsomal $\mathrm{Ca} 2+$ flux modulation as an indicator of heavy metal toxicity. Indian $\mathrm{J}$ Exp Biol 48: 737-743.

45. Yang Y, Jing XP, Zhang SP, Gu RX, Tang FX, et al. (2013) High dose zinc supplementation induces hippocampal zinc deficiency and memory impairment with inhibition of BDNF signaling. PLoS One 8: 55384.

46. Araujo JA (2010) Particulate air pollution, systemic oxidative stress, inflammation, and atherosclerosis. Air Qual Atmos Health 4: 79-93.

47. Terzano C, Di Stefano F, Conti V, Graziani E, Petroianni A (2010) Air pollution ultrafine particles: toxicity beyond the lung. Eur Rev Med Pharmacol Sci 14 809-821.

48. Krivoshto IN, Richards JR, Albertson TE, Derlet RW (2008) The toxicity of diesel exhaust: implications for primary care. J Am Board Fam Med 21: 55-62.

49. Pope CA 3rd, Dockery DW (2006) Health effects of fine particulate air pollution: lines that connect. J Air Waste Manag Assoc 56: 709-42.

50. Clean Air Task Force (CATF) (2005) Diesel and Health in America: The Lingering Threat. CATF, Boston, USA.

51. Clean Air Task Force (CATF) (2005) An Analysis of Diesel Air and Public Health in America. CATF, Boston, USA.

52. Kachuri L, Villeneuve PJ, Parent MÉ, Johnson KC, Canadian Cancer Registries Epidemiology Research Group, et al. (2016) Workplace exposure to diesel and gasoline engine exhausts and the risk of colorectal cancer in Canadian men. Environ Health 15: 4.

53. Zheng Z, Zhang X, Wang J, Dandekar A, Kim H, et al. (2015) Exposure to fine airborne particulate matters induces hepatic fibrosis in murine models. Hepatol 63: 1397-1404

54. Goldberg MS, Parent ME, Siemiatycki J, Désy M, Nadon L, et al. (2001) A case-control study of the relationship between the risk of colon cancer in men and exposures to occupational agents. Am J Ind Med 39: 531-546.

55. Dybdahl M, Risom L, Møller $\mathrm{P}$, Autrup $\mathrm{H}$, Wallin $\mathrm{H}$, et al. (2003) DDNA adduct formation and oxidative stress in colon and liver of Big Blue rats after dietary exposure to diesel particles. Carcinogenesis 24: 1759-1766.

56. Mutlu EA, Engen PA, Soberanes S, Urich D, Forsyth CB, et al. (2011) Particulate matter air pollution causes oxidant-mediated increase in gut permeability in mice. Part Fibre Toxicol 8: 19.
57. Boorman G, Ernst H, Harkema J, Hubbs A, Renne R, et al. (2015) Pathology Working group report and comparison statement. In: Greenbaum DS, O'Keefe RM, Shaikh R, Gale B, Adams K (eds.). Advanced Collaborative Emissions Study (ACES), Lifetime Cancer and Non-Cancer Assessment in Rats Exposed to New-Technology Diesel Exhaust. Health Effects Institute, Boston, USA. Pg: 40,51,57,61

58. Shichijo S, Hirata Y, Sakitani K, Yamamoto S, Serizawa T, et al. (2015) Distribution of intestinal metaplasia as a predictor of gastric cancer development. J Gastroenterol Hepatol 30: 1260-1264.

59. McEvoy MP, Coopey SB, Mazzola E, Buckley J, Belli A, et al. (2015) Breast Cancer Risk and Follow-up Recommendations for Young Women Diagnosed with Breast Cancer Risk and Follow-up Recommendations for Young Women Diagnosed with Atypical Hyperplasia and Lobular Carcinoma In Situ (LCIS). Ann Surg Oncol 22: 3346-3349.

60. Greenberg AK, Yee H, Rom WN (2002) Preneoplastic lesions of the lung Respir Res 3: 20.

61. Sterner DJ, Mori M, Roggli VL, Fraire AE (1997) Prevalence of pulmonary atypical alveolar cell hyperplasia in an autopsy population: a study of 100 cases. Mod Pathol 10: 469-473.

62. Yokose T, Ito Y, Ochiai A (2000) High prevalence of atypical adenomatous hyperplasia of the lung in autopsy specimens from elderly patients with malignant neoplasms. Lung Cancer 29: 125-130.

63. Weng SY, Tsuchiya E, Kasuga T, Sugano H (1992) Incidence of atypical bronchioloalveolar cell hyperplasia of the lung: relation to histological subtypes of lung cancer. Virchows Arch A Pathol Anat Histopathol 420: 463-471.

64. Chapman AD, Kerr KM (2000) The association between atypical adenomatous hyperplasia and primary lung cancer. $\mathrm{Br} \mathrm{J}$ Cancer 83: 632-636.

65. Haschek WM, Rousseaux CG, Wallig MA (2009) Fundamentals of Toxicologic Pathology. ( $2^{\text {nd }}$ edn), Elsevier, London, UK.

66. Klebe S, Henderson DW (2013) Facts and fiction: premalignant lesions of lung tissues. Pathology 45: 305-315.

67. Makhijani A, Smith B, Thorne MC (2006) Science for the Vulnerable: Setting Radiation and Multiple Exposure Standards. Institute for Energy and Environmental Research, Maryland, USA.

68. Newschaffer CJ, Croen LA, Daniels J, Giarelli E, Grether JK, et al. (2007) The epidemiology of autism spectrum disorders. Annu Rev Public Health 28 $235-258$

69. Thanan R, Oikawa S, Hiraku Y, Ohnishi S, Ma N, et al. (2014) Oxidative stress and its significant roles in neurodegenerative diseases and cancer. Int J Mol Sci 16: 193-217.

70. Hecht F, Pessoa CF, Gentile LB, Rosenthal D, Carvalho DP, et al. (2016) The role of oxidative stress on breast cancer development and therapy. Tumour Biol 37: 4281-4291.

71. Gorrini C, Harris IS, Mak TW (2013) Modulation of oxidative stress as an anticancer strategy. Nat Rev Drug Discov 12: 931-947.

72. Rakoff-Nahoum S (2006) Why cancer and inflammation? Yale J Biol Med 79: $123-130$

73. Reuter S, Gupta SC, Chaturvedi MM, Aggarwal BB (2010) Oxidative stress, inflammation, and cancer: how are they linked? Free Radic Biol Med 49: 1603-1616.

74. Conklin DJ, Kong M, HEI Health Review Committee (2015) Part 4. Assessment of plasma markers and cardiovascular responses in rats after chronic exposure to new-technology diesel exhaust in the ACES bioassay. Res Rep Health Eff Inst 184: 111-139.

75. Bemis JC, Torous DK, Dertinger SD (2015) Part 2. Assessment of Micronucleus Formation in Rats after Chronic Exposure to New-Technology Diesel Exhaust in the ACES bioassay. Res Rep Health Eff Inst 184: 69-82.

76. Pusateri A, Shrader-Frechette K (2015) Commentary: Flawed scientific-evidence standards delay diesel regulations. Account Res 22: 162-191. 
Citation: Shrader-Frechette K, McQuestion C (2016) "Special-Interest Science" Harms Diesel-Polluted Communities Like East Los Angeles. J Community Med Public Health Care 3: 016.

77. Michaels D (2008) Doubt is Their Product. Oxford University Press, Oxford UK.

78. Krimsky S, Nader Ralph (2004) Science in the Private Interest: Has the Lure of Profits Corrupted Biomedical Research? Rowman and Littlefield, Maryland, USA.

79. Shrader-Frechette K (2007) Taking Action, Saving Lives. Oxford University Press, New York City, USA

80. Beder S (1998) Global Spin: The Corporate Assault on Environmentalism (2ndedn), Chelsea Green Publishing Company, Vermont, USA.

81. Yach D (2000) Global Dialogue for Health. Tobacco Free Initiative, WHO, Geneva, Switzerland.

82. Shrader-Frechette K (2014) Tainted. Oxford University Press, New York City, USA.

83. Liu L, Yu LY, Mu HJ, Xing LY, Li YX, et al. (2014) Shape of concentration-response curves between long-term particulate matter exposure and morbidities of chronic bronchitis: a review of epidemiological evidence. J Thorac Dis 6: $720-727$.

84. Wilhelm M, Ghosh JK, Su J, Cockburn M, Jerrett M, et al. (2012) Traffic-related air toxics and term low birth weight in Los Angeles County, California. Environ Health Perspect 120: 132-138.

85. Nelin TD, Joseph AM, Gorr MW, Wold LE (2012) Direct and indirect effects of particulate matter on the cardiovascular system. Toxicol Lett 208: 293-299.

86. Valavanidis A, Vlachogianni T, Fiotakis K, Loridas S (2013) Pulmonary oxidative stress, inflammation and cancer: respirable particulate matter, fibrous dusts and ozone as major causes of lung carcinogenesis through reactive oxygen species mechanisms. Int J Environ Res Public Health 10: 3886-3907.

87. Schwartz J, Zanobetti A (2000) Using meta-smoothing to estimate dose-response trends across multiple studies, with application to air pollution and daily death. Epidemiology 11: 666-672.

88. Daniels MJ, Dominici F, Samet JM, Zeger SL (2000) Estimating particulate matter-mortality dose-response curves and threshold levels: an analysis of daily time-series for the 20 largest US cities. Am J Epidemiol 152: 397-406.

89. Dominici F, Daniels M, Zeger SL, Samet JM (2002) Air pollution and mortality. J Am Stat Assoc 97: 100-111.

90. Dominici F, Peng RD, Bell ML, Pham L, McDermott A, et al. (2006) Fine particulate air pollution and hospital admission for cardiovascular and respiratory diseases. JAMA 295: 1127-1134.

91. Boldo E, Linares C, Lumbreras J, Borge R, Narros A, et al. (2011) Health impact assessment of a reduction in ambient PM (2.5) levels in Spain. Environ Int 37: 342-348.

92. Laden F, Schwartz J, Speizer FE, Dockery DW (2006) Reduction in fine particulate air pollution and mortality: Extended follow-up of the Harvard Six Cities study. Am J Respir Crit Care Med 173: 667-672.

93. Hill LB, Zimmerman NJ, Gooch, J (2005) A Multi-City Investigation of the Effectiveness of Retrofit Emissions Controls in Reducing Exposures to Particulate Matter in School Buses. Clean Air Task Force, Boston, USA.

94. http://www.catf.us/methane/black_carbon/diesel/dieselhealth/

95. Borgie M, Dagher Z, Ledoux F, Verdin A, Cazier F, et al. (2015) Comparison between ultrafine and fine particulate matter collected in Lebanon: Chemical characterization, in vitro cytotoxic effects and metabolizing enzymes gene expression in human bronchial epithelial cells. Environ Pollut 205: 250-260.

96. Lin B, Li X, Zhang H, Lin Z, Tian L, et al. (2014) Comparison of in vitro toxicity of mainstream cigarette smoke particulate matter from nano- to micro-size. Food Chem Toxicol 64: 353-360.

97. Li N, Sioutas C, Cho A, Schmitz D, Misra C, et al. (2003) Ultrafine particulate pollutants induce oxidative stress and mitochondrial damage. Environ Health Perspect 111: 455-460
98. Li R, Ning Z, Cui J, Khalsa B, Ai L, et al. (2009) Ultrafine particles from diese engines induce vascular oxidative stress via JNK activation. Free Radic Biol Med 46: 775-782.

99. Rückerl R, Phipps RP, Schneider A, Frampton M, Cyrys J, et al. (2007) UItrafine particles and platelet activation in patients with coronary heart disease--results from a prospective panel study. Part Fibre Toxicol 4: 1.

100. Delfino RJ, Staimer N, Tjoa T, Gillen DL, Polidori A, et al. (2009) Air pollution exposures and circulating biomarkers of effect in a susceptible population: clues to potential causal component mixtures and mechanisms. Environ Health Perspect 117: 1232-1238.

101.Song S, Lee K, Lee YM, Lee JH, Lee SI, et al. (2011) Acute health effects of urban fine and ultrafine particles on children with atopic dermatitis. Environ Res 111: 394-399.

102. Karthikeyan S, Thomson EM, Kumarathasan P, Guénette J, Rosenblatt D, et al. (2013) Nitrogen dioxide and ultrafine particles dominate the biological effects of inhaled diesel exhaust treated by a catalyzed diesel particulate filter. Toxicol Sci 135: 437-450

103. Khalek IA, Bougher TL, Merritt PM, Zielinska B (2011) Regulated and unregulated emissions from highway heavy-duty diesel engines complying with U.S. Environmental Protection Agency 2007 emissions standards. J Air Waste Manag Assoc 61: 427-442.

104. Kittelson DB, Watts WF, Johnson JP, Thorne C, Higham C, et al. (2008) Effect of fuel and lube oil sulfur on the performance of a diesel exhaust gas continuously regenerating trap. Environ Sci Technol 42: 9276-9282.

105.Ana GREE, Sridhar MKC, Nriagu J (2013) Spatial Variations of Particle-Bound Trace Metals in Ambient Air of Selected Niger Delta Communities of Rivers State, Nigeria. Journal of Environmental Protection 4: 1502-1509.

106. Bellinger DC (2004) Lead. Pediatrics 113: 1016-1022.

107.Bellinger DC (2008) Very low lead exposures and children's neurodevelopment. Curr Opin Pediatr 20: 172-177.

108.Lanphear BP, Hornung R, Khoury J, Yolton K, Baghurst P, et al. (2005) Low-Level Environmental Lead Exposure and Children's Intellectual Function: An International Pooled Analysis. Environ Health Perspect 113: 894849

109.Zahran S, Mielke HW, Weiler S, Berry KJ, Gonzales C (2009) Children's blood lead and standardized test performance response as indicators of neurotoxicity in metropolitan New Orleans elementary schools. Neurotoxicology 30: 888-897.

110.Zahran S, Mielke HW, Weiler S, Gonzales CR (2011) Nonlinear associations between blood lead in children, age of child, and quantity of soil lead in metropolitan New Orleans. Sci Total Environ 409: 1211-1218.

111. Williams SC (2013) Alzheimer's disease: Mapping the brain's decline. Nature 502: 84-85.

112. Fiebig M, Wiartalla A, Holderbaum B, Kiesow S (2014) Particulate emissions from diesel engines: correlation between engine technology and emissions. J Occup Med Toxicol 9: 6.

113. Northeast Diesel Collaborative (2006) Diesel Particulate Filters and Ultrafine Particles. Northeast Diesel Collaborative, Boston, USA

114. Air Resources Board (2012) Status of Research on Potential Mitigation Concepts to Reduce Exposure to Nearby Traffic Pollution. Air Resources Board Sacramento, California, USA

115. Air Resources Board (2007) Fugitive Dust Control. Air Resources Board, Sacramento, California, USA

116.https://www3.epa.gov/region9/ej/enforcement.html 
Citation: Shrader-Frechette K, McQuestion C (2016) "Special-Interest Science" Harms Diesel-Polluted Communities Like East Los Angeles. J Community Med Public Health Care 3: 016.

- Page 10 of $10 \cdot$

117.California Air Resources Board (2008) Diesel Particulate Matter Health Risk Assessment for the West Oakland Community: Preliminary Summary of Results. California Air Resources Board, Sacramento, California, USA.
118.Smith RF, Jia X, Mariappan J (2008) Electrification of the freight train network from the ports of Los Angeles and Long Beach to the Inland Empire. California State Polytechnic University, Pomona, California, USA. 